\title{
A comparative study of the anti-nociceptive potential of duloxetine and carbamazepine in an animal model of neuropathic pain
}

\author{
Saurabh Kohli*, Taruna Sharma, Juhi Kalra, Dilip C. Dhasmana
}

\begin{abstract}
Department of Pharmacology, Himalayan Institute of Medical Sciences, Dehradun, Uttarakhand, India
\end{abstract}

Received: 16 December 2015 Accepted: 30 December 2015

\section{*Correspondence to: \\ Dr. Saurabh Kohli, Email:drskohli@gmail.com}

Copyright: (C) the author(s), publisher and licensee Medip Academy. This is an openaccess article distributed under the terms of the Creative Commons Attribution NonCommercial License, which permits unrestricted noncommercial use, distribution, and reproduction in any medium, provided the original work is properly cited.

\begin{abstract}
Background: Pain is one of the most common symptoms encountered in clinical practice. Of the various types of pain, neuropathic pain represents one of the most difficult pain states to treat, with treatments being far from satisfactory. The drugs used are not fully effective and a drug that shows good efficacy in one neuropathic pain state may be ineffective in another. This study was done to compare the antinociceptive potential of duloxetine and carbamazepine, two drugs with different mechanisms of action in an animal model of neuropathic pain.

Methods: Antinociceptive effect of duloxetine $(15 \mathrm{mg} / \mathrm{kg}$ intraperitoneally) and carbamazepine $(20 \mathrm{mg} / \mathrm{kg}$ intraperitoneally) was evaluated in the sciatic chronic constriction injury (CCI) model of neuropathic pain in rats. Thermal hyperalgesia, evaluated by the hot plate method; and mechanical hyperalgesia, evaluated by the pinprick method were used as measures of neuropathic pain.

Results: A significant degree of thermal and mechanical hyperalgesia $(p \leq 0.05)$ was produced in both the drug groups. Both drugs produced a significant decrease in thermal and mechanical hyperalgesia throughout the study period ( $\mathrm{p}$ $\leq 0.01$ for both drugs). In comparison to duloxetine, carbamazepine was less efficacious ( $p \leq 0.05$ at 30,60 minutes; $p \leq 0.01$ at 120 minutes) for thermal hyperalgesia as well as for mechanical hyperalgesia ( $\mathrm{p} \leq 0.05$ at 30,60 minutes; $\mathrm{p} \leq 0.01$ at 120 minutes). Only duloxetine was able to almost completely reverse both thermal \& mechanical hyperalgesia to near pre-neuropathy levels.

Conclusions: Duloxetine showed better antinociceptive potential as compared to carbamazepine as reflected by a more complete reduction in thermal \& mechanical hyperalgesia in the sciatic CCI model of neuropathic pain.
\end{abstract}

Keywords: Neuropathic pain, Duloxetine, Carbamazepine, Antinociceptive

\section{INTRODUCTION}

Neuropathic pain is defined as pain resulting from injury to or dysfunction of the somatosensory system. ${ }^{1}$ It is a complex disorder characterized by multiple etiologies, symptoms and underlying mechanisms. More than a hundred different types of neuropathic pain states are known, with the most common being radiculopathies, diabetic polyneuropathy, and nerve trauma, including postsurgical neuralgia. This wide variety as well as the complex pathophysiological mechanisms involved makes it one of the most challenging of pain states to treat. NSAIDs are usually ineffective and non-conventional drugs form the mainstay of treatment. These drugs include certain antidepressants and anticonvulsants, drugs acting on $\gamma$-amino butyric acid (GABA) receptors and on various ion channels, alpha adrenergic agonists, and more recently drugs affecting the cannabinoid system are gaining importance. ${ }^{2}$ But no drug, whether conventional or non-conventional, is fully effective in the treatment of this condition, and a drug that shows good efficacy in one neuropathic pain state may be ineffective in another. Present treatment modalities provide clinically significant i.e. greater than $50 \%$ pain relief in only around $60 \%$ of patients. $^{3,4}$ Duloxetine and pregabalin, recommended as $1^{\text {st }}$ line drugs in neuropathic pain are only approved for diabetic peripheral neuropathy \& post herpetic neuralgia by the US FDA. Their efficacies in traumatic \& postsurgical neuropathic pain are not fully known. Thus, there is an unmet need for the use of drugs with different mechanisms of action to be tried in neuropathic pain states. 
Unlike other types of pain, the paucity of human volunteer models for neuropathic pain means that animal models, in spite of their shortcomings, are the mainstay of research; with rodent models, especially rat models being by far the most commonly used. ${ }^{3}$ Of the models used Sciatic nerve CCI resembles human neuropathy resulting from trauma of peripheral nerves, with some functional preservation of the innervation (nerve entrapment or compression). The model of CCI is one of the most commonly used models because it is reliable and easily reproducible. ${ }^{5}$

\section{METHODS}

Approval was taken from the IAEC (HIHT/PHARMA/I$1 / 2010 / 1816$ ) prior to the conduct of the study. Adult Sprague-Dawley albino rats of either sex \& weighing 100-300 grams were used for the experiments. Animals were housed in a group of 4-6/cage for 1 month and food and water were provided ad libitum. Neuropathic pain was produced using the sciatic nerve chronic constriction injury model; and 14 days after sciatic nerve ligation thermal \& mechanical hyperalgesia were tested as a measure of neuropathic pain. Thermal hyperalgesia was tested by the hot-plate method; \& mechanical hyperalgesia by the pin prick method. Commercial preparations of Duloxetine (Talent India) \& carbamazepine (Sun Pharmaceuticals, India) dissolved in normal saline and dimethyl sulphoxide respectively, were evaluated for their anti-nociceptive potential. After an overnight fast, duloxetine and carbamazepine were given once intraperitoneally (i.p) 30 minutes before the experimentations in a dose of $15 \mathrm{mg} / \mathrm{kg}$ and $20 \mathrm{mg} / \mathrm{kg}$ respectively. ${ }^{6-8}$ All the experiments were done at the same time in the morning hours on all days of experimentation. Observations were recorded over a period of 2 hours. The albino rats were divided into 3 groups, each consisting of 6 rats (Table 1). A sham operated group was taken in which the sciatic nerve was exposed but not ligated. This was done to rule out the effect of the surgical procedure in the production of the neuropathy.

\section{Procedures: induction of neuropathy}

\section{Sciatic nerve ligation (Bennett and Xie model)}

After induction of anaesthesia with ketamine $(75 \mathrm{mg} / \mathrm{kg})$ and xylazine $(10 \mathrm{mg} / \mathrm{kg})$ intraperitoneally, using aseptic precautions, a local incision was given at mid-thigh level and the biceps femoralis bluntly dissected to expose the sciatic nerve. ${ }^{9}$ Four chromic catgut sutures (4-0) were tied loosely around the nerve until the nerve was just indented, and the incision was closed. Maximum hyperesthesia occurs 7-14 days after ligation. ${ }^{10}$ Thermal and mechanical hyperalgesia were tested on the $14^{\text {th }}$ day by the following tests over a period of 2 hours.

A. Mechanical hyperalgesia: This was measured by the pin prick test. The plantar surface of the hind paws of the rats was touched with the point of a safety pin, applying a force that indented but did not puncture the skin. A normal pinprick hind paw withdrawal was arbitrarily assigned a duration of 0.5 seconds. A hyperalgesic withdrawal response was defined as being abnormally prolonged if it lasted for at least 2 seconds and a cut-off of 15 seconds was applied ${ }^{11}$

B. Thermal hyperalgesia: This was assessed using a hot plate. Rats were placed on a hot plate and the temperature adjusted to $50-52$ degrees Celsius. The latency of the first reaction (licking, jumping, moving paws, little leaps etc.) was recorded, with a cutoff of 60 seconds. ${ }^{12}$

\section{Statistical analysis}

Interpretation and analysis of the obtained results was carried out using the 'student t test' using Microsoft Excel 2007. The paired ' $t$ ' test was used to evaluate the antinociceptive potential of both the drugs in reversing the neuropathy produced; while the unpaired ' $t$ ' test was used to compare the anti-nociceptive potential of both the drugs at different time points.

\section{RESULTS}

Readings were taken before neuropathy was produced (pre-neuropathy values); on the $14^{\text {th }}$ day, after neuropathy had been produced but just prior to drug administration ( 0 minute values); and at 30, 60 and 120 minutes after drug administration. Observations were compared between:-

1. Pre-neuropathy values and 0 minute values, to assess whether a significant neuropathy was produced in each group.

2. 0 minute values were compared with 30,60 and 120 minute values, to assess whether the drug given had any significant effect in reversing the neuropathic pain and whether the effect was sustained over a period of 2 hours.

3. Pre- neuropathy values were compared with 30,60 and 120 minute values, to assess how effective the drugs were in reversing the neuropathic pain towards normal (i.e. pre-neuropathy).

4. Duloxetine \& carbamazepine were compared by comparing the change in effect at 30 minutes, 60 minutes and 120 minutes.

For both thermal hyperalgesia (Table 2) and mechanical hyperalgesia (Table 3), no significant difference between the pre-neuropathy values in each group and the sham operated groups was observed, thus establishing that the neuropathy produced was not due to surgical trauma and that the surgical procedure did not have any confounding effect on the observations. A statistically significant degree of thermal and mechanical hyperalgesia $(p \leq 0.05)$ was produced by day $14^{\text {th }}$ in the drug groups in comparison to pre-neuropathy values. Both the drugs produced a significant decrease in thermal hyperalgesia which was sustained throughout the two hour study 
period ( $\mathrm{p} \leq 0.001$ for both duloxetine and carbamazepine). But only duloxetine was able to reverse the thermal hyperalgesia to pre-neuropathy levels and this effect was maintained over the two hour study period ( $p>0.05$ at 30 ,
60 and 120 minutes). Carbamazepine was not able to fully reverse the thermal hyperalgesia to pre-neuropathy levels during the two hour study period $(\mathrm{p} \leq 0.01)$ (Table 2).

Table 1: Groups \& drug schedule.

\begin{tabular}{|lllll|}
\hline Group & No. of albino rats & Weight $(\mathrm{gms})$ Mean \pm SE & Drug & Dose \& route \\
\hline Sham operated & 6 & $131.66 \pm 12.48$ & Normal saline & $0.5 \mathrm{ml}$ intraperitoneally \\
\hline Duloxetine group & 6 & $131.66 \pm 9.8$ & Duloxetine & $15 \mathrm{mg} / \mathrm{kg}$ intraperitoneally \\
\hline Carbamazepine group & 6 & $140 \pm 8.55$ & Carbamazepine & $20 \mathrm{mg} / \mathrm{kg}$ intraperitoneally \\
\hline
\end{tabular}

Table 2: Effects of sham operation and experimental drugs on thermal hyperalgesia (latency to first reaction in seconds, expressed as mean \pm S.E.) in the sciatic nerve ligation model.

\begin{tabular}{|c|c|c|c|c|c|}
\hline \multirow[t]{2}{*}{ Group } & \multicolumn{5}{|c|}{ Observations (seconds) Mean \pm SE } \\
\hline & Pre- neuropathy & $0 \mathrm{~min}$ & $30 \mathrm{~min}$ & $60 \mathrm{~min}$ & $120 \mathrm{~min}$ \\
\hline Sham & $43.66 \pm 2.02$ & $43.83 \pm 2.41$ & $42.83 \pm 2.57$ & $42.16 \pm 2.24$ & $43 \pm 2.09$ \\
\hline $\begin{array}{l}\text { Duloxetine (15 } \\
\text { mg/kg i.p.) }\end{array}$ & $41.5 \pm 2.66$ & $21.66 \pm 1.47^{* * *}$ & $40 \pm 3.49^{\dagger+\dagger}$ & $42 \pm 4.01^{\dagger \dagger \dagger}$ & $41.66 \pm 2.85^{\dagger \dagger \dagger}$ \\
\hline $\begin{array}{l}\text { Carbamazepine } \\
(20 \mathrm{mg} / \mathrm{kg} \text { i.p. })\end{array}$ & $41.33 \pm 1.70$ & $19 \pm 1.09^{* * *}$ & $30.33 \pm 1.78^{* *}$ & $30.83 \pm 1.83 * * \dagger \dagger$ & $31.33 \pm 1.44^{* * \dagger \dagger \dagger}$ \\
\hline
\end{tabular}

** $\mathrm{p} \leq 0.01$ vs pre-neuropathy values; $* * * \mathrm{p} \leq 0.001$ vs pre-neuropathy values; $\dagger \dagger \mathrm{p} \leq 0.01$ vs values at 0 minutes (just prior to drug administration); $\uparrow \dagger \mathrm{p} \leq 0.001$ vs values at 0 minutes (just prior to drug administration)

Table 3: Effects of sham operation and experimental drugs on mechanical hyperalgesia (duration of reaction in seconds, expressed as mean \pm S.E.) in the sciatic nerve ligation model.

\begin{tabular}{|llllll|}
\hline Group & \multicolumn{2}{l}{ Observations (seconds) } & \multicolumn{3}{c|}{ Mean \pm SE } \\
\hline Sham & Pre- neuropathy & $0 \mathrm{~min}$ & $30 \mathrm{~min}$ & $60 \mathrm{~min}$ & $120 \mathrm{~min}$ \\
\hline $\begin{array}{l}\text { Duloxetine } \\
(15 \mathrm{mg} / \mathrm{kg} \text { i.p. })\end{array}$ & $0.5 \pm 0$ & $0.5 \pm 0$ & $0.5 \pm 0$ & $0.5 \pm 0$ & $0.5 \pm 0$ \\
\hline $\begin{array}{l}\text { Carbamazepine } \\
(20 \mathrm{mg} / \mathrm{kg} \text { i.p. })\end{array}$ & $0.5 \pm 0$ & $5.66 \pm 0.88 * *$ & $1.33 \pm 0.52 \uparrow \dagger$ & $1.33 \pm 0.58+\dagger$ & $1.75 \pm 0.61+\dagger$ \\
\hline
\end{tabular}

$* \mathrm{p} \leq 0.05$ vs pre-neuropathy values; $* * \mathrm{p} \leq 0.01$ vs pre-neuropathy values; $\dagger \dagger \mathrm{p} \leq 0.01$ vs values at 0 minutes (just prior to drug administration); $\dagger \dagger \mathrm{p} \leq 0.001$ vs values at 0 minutes (just prior to drug administration)

Table 4: Effects of drugs (expressed as mean change in reaction times $\pm \mathrm{S}$.E from 0 minute values) in the sciatic nerve ligation model for testing thermal \& mechanical hyperalgesia.

\begin{tabular}{|lllllll|}
\hline Group & \multicolumn{2}{l}{$\begin{array}{l}\text { Thermal hyperalgesia observations (seconds) } \\
\text { Mean } \pm \text { SE }\end{array}$} & \multicolumn{3}{l|}{$\begin{array}{l}\text { Mechanical hyperalgesia observations } \\
\text { (seconds) Mean } \pm \text { SE }\end{array}$} \\
\hline & $30 \mathrm{~min}$ & $60 \mathrm{~min}$ & $120 \mathrm{~min}$ & $30 \mathrm{~min}$ & $60 \mathrm{~min}$ & $120 \mathrm{~min}$ \\
\hline $\begin{array}{l}\text { Duloxetine } \\
(15 \mathrm{mg} / \mathrm{kg} \text { i.p) }\end{array}$ & $18.33 \pm 2.45$ & $20.8 \pm 3.01$ & $20 \pm 1.94$ & $4.33 \pm 0.66$ & $4.33 \pm 0.66$ & $4.16 \pm 0.65$ \\
\hline $\begin{array}{l}\text { Carbamazepine } \\
(20 \mathrm{mg} / \mathrm{kg} \text { i.p. })\end{array}$ & $11.33 \pm 1.30 *$ & $11.83 \pm 1.27 *$ & $\begin{array}{l}12.33 \pm \\
1.35 * *\end{array}$ & $2.5 \pm 0.28 *$ & $2.33 \pm 0.27 *$ & $1.83 \pm 0.33 * *$ \\
\hline
\end{tabular}

$* \mathrm{P} \leq 0.05$ vs duloxetine; $* * \mathrm{P} \leq 0.01$ vs duloxetine 
In comparison to duloxetine, carbamazepine was less efficacious in reversing thermal hyperalgesia $(p \leq 0.05$ at 30,60 minutes; $\mathrm{p} \leq 0.01$ at 120 minutes) (Table 4 ).

Duloxetine $(\mathrm{p} \leq 0.01$ at 30,60 and 120 minutes $) \&$ carbamazepine $(\mathrm{p} \leq 0.001$ at 30,60 minutes; $\mathrm{p} \leq 0.01$ at 120 minutes produced a significant decrease in mechanical hyperalgesia and this was sustained throughout the two hour study period. Duloxetine reversed the mechanical hyperalgesia to near normal levels throughout the two hour study period ( $p>0.05$ at 30,60 and 120 minutes) while carbamazepine reversed it to near control values at 30 and 60 minutes $(p>0.5)$ but the effect waned by 120 minutes, reaching statistically significant levels $(p \leq 0.05)$ at this time period (Table 3).

In comparison to duloxetine, carbamazepine ( $\mathrm{p} \leq 0.05$ at 30, 60 minutes; $\mathrm{p} \leq 0.01$ at 120 minutes) was less efficacious in reversing mechanical hyperalgesia as reflected by a statistically significant difference for the drugs at 30, 60 and 120 minutes (Table 4).

\section{DISCUSSION}

The present study was done to compare the antinociceptive potential of duloxetine which is a Serotonin Norepinephrine Reuptake Inhibitor (SNRI) and carbamazepine (a sodium channel blocker) in the CCI model of neuropathic pain. This model resembles human neuropathy resulting from trauma of peripheral nerves. ${ }^{5}$ A sham operated group was taken to rule out the effect of the surgical procedure in the production of the neuropathy. Duloxetine is approved as first line treatment in diabetic peripheral neuropathy \& post herpetic neuralgia, but it has not been adequately studied in neuropathic pain due to trauma of peripheral nerves. Similarly, carbamazepine is approved as first line drug in trigeminal neuralgia but it too has not been adequately studied in neuropathy resulting from trauma of peripheral nerves. ${ }^{13}$ In animal models of neuropathic pain, these drugs have been tried individually with varying results; but head to head comparisons of these drugs are scarce.

Duloxetine has also shown good efficacy in different models of neuropathic pain. In a study utilizing the CCI model of neuropathic pain, duloxetine in a dose of 3-30 $\mathrm{mg} / \mathrm{kg}$ i.p significantly reversed both thermal and mechanical hyperalgesia in a dose dependent manner. Duloxetine completely reversed the thermal hyperalgesia, though mechanical hyperalgesia was not completely reversed. ${ }^{14}$ This is in contrast to our study, where a complete reversal for both thermal and mechanical hyperalgesia was seen at doses of $15 \mathrm{mg} / \mathrm{kg}$ i.p. Variations in the results are known to occur with different strains of animals; and observer variation may also be present. In another study in rodents utilizing the spinal nerve ligation model of peripheral neuropathy, duloxetine $5-30 \mathrm{mg} / \mathrm{kg}$ p.o produced a dose dependent, but not a complete reversal of mechanical allodynia; and this effect was greater than the other SNRIs venlafaxine and milnacipran. The effect on thermal hyperalgesia was not studied. ${ }^{6}$

Various animal and clinical studies have demonstrated carbamazepine to be effective in the treatment of peripheral neuropathic pain, especially diabetic and post herpetic neuropathic pain. ${ }^{15}$ In a study in humans stratified according to pain phenotypes, oxcarbazepine was found more efficacious for relief of peripheral neuropathic pain in patients with the irritable versus the nonirritable nociceptor phenotype. ${ }^{16}$ Another study utilizing the CCI model compared gabapentin (a first line drug in neuropathic pain), carbamazepine \& lamotrigine. This study showed that carbamazepine was superior to both the drugs in reversing thermal hyperalgesia; though its effect on mechanical hyperalgesia was less as compared to the other two drugs. ${ }^{17}$ In other studies involving rodents, carbamazepine in various doses has been shown to produce a significant, but not complete reversal of thermal hyperalgesia. The effect on mechanical hyperalgesia \& mechanical allodynia were weak. $^{11,18}$

In the present study, carbamazepine in a dose of 20 $\mathrm{mg} / \mathrm{kg}$ i.p. though effective in reducing both the thermal and mechanical hyperalgesia was not as effective as duloxetine.

In conclusion, our study showed that duloxetine \& carbamazepine both were effective in reducing thermal \& mechanical hyperalgesia produced by CCI of the sciatic nerve; though duloxetine was clearly superior to carbamazepine. But, the multitude of neuropathic pain states \& the complex pathophysiological mechanisms involved means that a drug effective in one pain state may not be effective in another; and the response produced may also not be adequate. Thus, there is a continuing need to evaluate newer drugs with different mechanisms of action in various models of neuropathic pain.

\section{ACKNOWLEDGEMENTS}

I am thankful to Dr. M.A Beg Associate Professor, Department of Pharmacology SGRRMC, Dehradun for his invaluable help in the completion of this project.

Funding: No funding sources

Conflict of interest: None declared

Ethical approval: The study was approved by the Institutional Ethics Committee ((HIHT/PHARMA/I1/2010/1816)

\section{REFERENCES}

1. Treede RD, Jensen TS, Campbell JN, Cruccu G, Dostrovsky JO, Griffin JW et al. Neuropathic pain: redefinition and a grading system for clinical and research purposes. Neurology. 2008;70:1630-5. 
2. Knotova H, Pappagallo M. Adjuvant analgesics. Med Clin N Am. 2007;91:113-24

3. Bridges D, Thompson SWN, Rice ASC. Mechanisms of neuropathic pain. Br J Anaesth. 2001;87(1):12-26.

4. Saxena AS, Azad R. Advances in the mechanisms, diagnosis and management of neuropathic pain: current opinions and future perspectives. Indian J Anaesth. 2006;50(4):249-57.

5. Colleoni M, Sacerdote P. Murine models of human neuropathic pain. Biochimica et Biophysica Acta. 2010;1802(10):924-33

6. Iyenger S, Amy A, Webster AA, Hamrick-Luieke SK, Xu JY, Simmons RMA. Efficacy of duloxetine, a potent balanced serotonin-norepinephrine reuptake inhibitor in persistent pain models in rats. J Pharmacol Exp Ther. 2004;311:576-84.

7. Gordon BM, Nete I, Helle E. A comparison of the antinociceptive effects of voltage activated sodium channel blockers in the formalin test. Eur J Pharmacol. 2002;445(3):231-8.

8. Todorovic SM, Rastogi AJ, Todorovic VJ. Potent analgesic effects of anticonvulsants on peripheral thermal nociception in rats.Br $\mathrm{J}$ Pharmacol. 2003; 140:255-60.

9. Liu L, Zheng T, Morris MJ, Wallengren C, Clarke AL, Reid CA et al. The mechanism of carbamazepine aggravation of absence seizures. J Pharmacol Exp Ther. 2000;319:790-8.

10. Vogel GH, Vogel WGH, editors, Drug discovery and evaluation- pharmacological assays. $2^{\text {nd }}$ ed. New York: Verlog Springer publication, 1996.

11. Gonzalez MI, Field MJ, Hughes J, Singh L. Evaluation of the selective NK1 receptor antagonist CI-1021 in animal models of inflammatory and neuropathic pain. J Pharmacol Exp Ther. 2000;294(2):444-50.

12. Wang YX, Bowersox SS, Pettus M, Gao DA. Antinociceptive properties of fenfluramine, a serotonin reuptake inhibitor, in a rat model of neuropathy. J Pharmacol Exp Ther. 1999;291:100816.

13. Moulin DE, Boulanger A, Clark AJ, Clarke H, Dao T, Finley GA et al. Pharmacological management of chronic neuropathic pain: revised consensus statement from the Canadian Pain Society. Pain Res Manag. 2014;19(6):328-35.

14. Bomholt SF, Mikkelsen JP, Blackburn-Munro G. Antinociceptive effects of the antidepressants amitriptyline, duloxetine, mirtazapine and citalopram in animal models of acute, persistent and neuropathic pain. Neuropharmacology. 2005;48(2):252-63.

15. Golan DE, Tashjian AH, Armstrong EJ, editors. Principles of pharmacology- the pathophysiologic basis of drug therapy. $2^{\text {nd }}$ ed. New Delhi: Wolters Kluver(India) Pvt. Ltd, 2008.

16. Demant DT, Lund K, Vollert J, Maier C, Segerdahl M, Finnerup NB et al. The effect of oxcarbazepine in peripheral neuropathic pain depends on pain phenotype: a randomized, double-blind, placebo controlled phenotype stratified study. Pain. 2014;155(11):2263-73.

17. Chogtu B, Bairy KL, Himabindu P, Dhar S. Comparing the efficacy of carbamazepine, gabapentin and lamotrigine in chronic constriction injury model of neuropathic pain in rats. Int $\mathbf{J}$ Nutr Pharmacol Neurol Dis. 2013;3(1):34-8.

18. De Vry J, Kuhl E, Franken-Kunkel P, Eckel G. Pharmacological characterization of the chronic constriction injury model of neuropathic pain. Eur $\mathbf{J}$ Pharmacol. 2004;491(2-3):137-48.

Cite this article as: Kohli S, Sharma T, Kalra J, Dhasmana DC. A comparative study of the antinociceptive potential of duloxetine $\&$ carbamazepine in an animal model of neuropathic pain. Int $\mathbf{J}$ Basic Clin Pharmacol 2016;5:1-5. 